\title{
FUNDAMENTOS DE CRIOPRESERVACIÓN
}

\section{Basic points in cryopreservation}

\author{
Luz Mábel Ávila-Portillo, Bacter.*, Josél. Madero, M.D., MSc**, Claudia López, \\ Bacter.***, María Fernanda León, Bacter.***, Lucía Acosta, Bacter.****, Claudia \\ Gómez, M.D.****, Lucy Gabriela Delgado, PhD*****, Claudio Gómez, PhD*****, \\ José Manuel Lozano, PhD*****, María T. Reguero, PhD***** \\ Recibido: mayo 15/06 - Revisado: octubre 10/06 - Aceptado: octubre 19/06
}

\section{RESUMEN}

El entender y aplicar adecuadamente la criopreservación de material biológico es fundamental en laboratorios y bancos de células. Sin embargo aunque se han implementado protocolos para criopreservación, aún no se tienen los ideales en la mayoría de los casos.

El objetivo de esta revisión es dar a conocer ciertos parámetros inherentes al proceso de criopreservación y la importancia de conocer ciertas características de la célula que pueden incidir con la viabilidad del producto congelado para lograr la técnica adecuada. Para alcanzar este propósito, el documento se basará en el conocimiento de las propiedades fisicoquímicas de la célulaylo el tejido, pueseste proceso es afectado por diferentes variables como permeabilidad celular, volumen osmóticamente inactivo y relación superficie/área de la célula, la cual es variable de acuerdo a la especie, tipo y estadio de la célula a congelar. La estructura y composición de las membranas plasmáticas determinan los principales eventos celulares que tienen lugar durante los procesos de criopreservación; las bajas temperaturas afectan la difusión yósmosis através de las membranas y cada célula maneja su propio perfil biofísico el cual

\footnotetext{
* Candidata a D octor en Ciencias Farmacéuticas, U niversidad Nacional de Colombia. Banco de Células Stem de Colombia. Hospital Militar Central. Correo electrónico: mabelavila us@ yahoo.com.

** Banco de Células Stem de Colombia. Medifértil.

*** Medifértil.

**** Banco de Células Stem de Colombia.

$* * * * *$ Profesor Universidad Nacional de Colombia.
}

interactúa con diferentes criopreservantes celulares. El hallar el protocolo adecuado será lo que garantice la viabilidad y funcionabilidad celular.

Palabras clave: criopreservación celular, células madre, Colombia.

\section{SUMMARY}

The appropriate understanding of and applying cryopreservation to biological material is fundamental for laboratories and cell-banks. However, although protocols have been implemented for cryopreservation, ideal standards arestill not being achieved or complied with in most cases. A suitable cryopreservation technique must be based on knowledge of a particular cell and/or tissue's physicochemical properties because cryopreservation is affected by different variables such as cellular permeability, osmotic inactive volume and a cell's surface/area relationship which varies according to the species, type and state of the cell to be frozen. Plasmatic membrane structure and composition determine the main cellular events taking place during cryopreservation; a drop in temperature affects diffusion and osmosis through membranes and each cell manages its own biophysical profile interacting with different cellular cryoprotectors. Cell viability and functionality can only be guaranteed by ensuring that an appropriate protocol is implemented and followed.

Key words: cellular cryopreservation, stem cells, Colombia. 


\section{INTRODUCCIÓN}

La criopreservación tiene como objetivo el mantenimiento de la viabilidad y funcionabilidad celular a temperaturas bajas. La criobiología se refiere a entender los efectos de las temperaturas bajas sobre los sistemas celulares ya que el tiempo bilóógico es una consecuencia de determinadas reacciones bioquímicas y el frío prolonga el tiempo biológico puesto que enlentece estas reacciones. Sin embargo, este no es un proceso exento de problemas ya que puede inducir variaciones extremas en las propiedades químicas, térmicas y eléctricas las cuales pueden alterar las membranas celulares, los organelos y la delicada interacción célula célula inherente en las células y tejidos a criopreservar. ${ }^{1}$

La estructura y composición de las membranas plasmáticas determinan los principales eventos celulares que tienen lugar durante los procesos de criopreservación, su comportamiento durante la congelación y descongelación definirálos índices de súpervivencia de la célula congelada. Los periodos críticos para la sobrevida celular durante la criopreservación son la fase inicial del congelamiento y el periodo de retorno a condiciones fisiológicas. ${ }^{2}$

El entender y aplicar adecuadamente la criopreservación de material biológico es fundamental para los bancos de células de humanos y de células animales, los laboratorios de cultivo celular (mantener una línea celular en cultivo continuo por largos periodos de tiempo es costosa, hay un gran riesgo de contaminación así como la posibilidad de una alteración genética) y los laboratorios de farmacia, por lo cual hay una especial atención a la conservación de tejidos, órganos y embriones humanos para ser utilizados en investigación y su posterior aplicación terapéutica (trasplantes) Ilegando a crear verdaderos archivos biológicos. ${ }^{3}$ Sin embargo, aunque desde hace mucho tiempo se han implementado protocolos para criopreservación, estos son aún subóptimos en la mayoría de los casos.

La obtención de un protocolo ideal para criopreservar es dependiente del conocimiento de las propiedades fisicoquímicas de la célula y o el tejido puesto que este proceso está afectado por diferentes variables como especie, tipo y estadio de la célula a congelar. ${ }^{4}$ Las células tienen diferente tamaño y manejan diferente composición de solutos y en general el éxito de la criopreservación es inversamente correlacionado con la complejidad de los sistemas biológicos congelados. Criopreservar células suele ser mas fácil a diferencia de hacerlo en ciertos tejidos como el testicular o el tejido ovárico pues su compartímentalización lo hace mucho mas complejo. ${ }^{3}$

La membrana plasmática de la célula eucariota, independientemente de su composición, tiene una estructura organizada según el modelo de mosaico fluido. ${ }^{5}$ Estas membranas se componen básicamente de lípidos amfipáticos, proteínas y un pequeño porcentaje de carbohidratos que es variable de acuerdo al tipo y especie celular. A modo de ejemplo, la membrana plasmática de los eritrocitos se compone de un $9 \%$ de proteína, un $43 \%$ de lípidos y un $8 \%$ de carbohidratos. ${ }^{6}$ Se debe tener en cuenta que el tamaño de partícula, la polaridad y la carga iónica determinan el paso a través de las membranas y de esa forma, pequeñas moléculas como las de agua (peso molecular PM: 18), etanol (PM : 46), glicerol (PM: 92) y oxígeno pasan a través de la membrana mientras que la glucosa (PM: 180) no lo hace. Cuanto menos polar es una molécula mas rápido puede pasar la membrana.

Los lípidos (colesterol y ácidos grasos) como componentes más abundantes de la membrana plasmática, determinan la fluidez y resistencia de la membrana durante los procesos de criopreservación. El empaquetamiento y la posición de estas moléculas en las bicapas determinarán la rigidez de las membranas y por tanto el transporte de moléculas. Este transporte a través de las membranas es el punto crítico para la súpervivencia celular posdescongelación.

En las bicapas, los ácidos grasos de los fosfolípidos se posicionan en paralelo los unos a los otros mientras que el colesterol se intercala entre ellos. Este empaquetamiento de las cadenas hidrofóbicas hace que interaccionen entre ellas y se estabilicen 
por fuerzas de van der Waals. Cuanto más difícil sea este empaquetamiento más fluida serála membrana. Cuanto más larga es la cadena del ácido graso, más fácilmente se forman estas uniones y mas rígida es la membrana, la existencia de dobles enlaces en las cadenas hidrofóbicas de los fosfolípidos de la membrana introduce cambios de orientación en las cadenas y hace que estas moléculas no interaccionen tan fácilmente entre sí y por tanto que la membrana sea más fluida. La presencia de moléculas de colesterol en la bicapa le proporciona rigidez a temperaturas fisiológicas por la unión de sus anillos a las cadenas de ácidos grasos (impide su libre movimiento y por tanto disminuye la fluidez) pero impide, por razones estéricas, que las cadenas de ácidos grasos se empaqueten libremente (cristalicen) al disminuir la temperatura aumentando, en ese momento, la fluidez de las membranas.?

Las membranas celulares son las estructuras que sufren mayor daño en los procesos de congelación en general debido a la pérdida de fluidez de sus componentes lipídicos, la transición de lípidos fluidos a sólidos se da a una temperatura de $10^{\circ} \mathrm{C}$ - $16^{\circ} \mathrm{C}$ alterando de esta manera las funciones de la membrana y dándole un alto grado de fragilidad, durante la deshidratación celular que tiene lugar en el proceso de congelación se puede presentar una pérdida de lípidos lo cual afectaría la integridad de la membrana plasmática por pérdida de su capacidad de expansión durante la rehidratación al volver a condiciones isotónicas. $^{8}$

\section{FUNDAMENTOS DE CRIOPRESERVACIÓN Transporte a través de las membranas durante la congelación y descongelación}

La bajas temperaturas (asociadas al aumento de la rigidez de la membrana) y la rapidez (décimas de segundo) con la que suceden los cambios osmóticos en los procesos de congelación y descongelación ha cen muy difícil el movimiento de moléculas através de la membrana mediante procesos de transporte activo (dependientes de ATP), la disminución de temperatura desde $25^{\circ} \mathrm{C}$ a $10^{\circ} \mathrm{C}$ reduce en un $60 \%$ la actividad de las bombas dependientes de ATP y la difusión facilitada o como transporte (transporte concomitante de dos moléculas a través de la membrana dependiente una de ellas de ATP y/o iones $\mathrm{H}^{+}$), en consecuencia, los procesos de difusión y ósmosis son los que predominan en los momentos de estrés osmótico. ${ }^{9}$

La difusión es un proceso mediante el cual las moléculas de una sustancia tienden a alcanzar una distribución homogénea en todo el espacio que les es accesible. La magnitud de la tendencia a difundir desde una zona a otra si esta presente una membrana que separe las dos zonas esta definida por la ley de difusión de Fick, que relaciona el gradiente entre las dos zonas (gradiente químico o de concentración), las características de lamembrana (grosor, áreade sección transversay permeabilidad paraun determinado soluto), es directamente proporcional a la superficie (área) de la membrana y a la diferencia de concentración del soluto entrelos dos lados e inversamente proporcional al espesor (grosor) de la membrana. La velocidad de la difusión es proporcional a una constante de difusión que depende de las propiedades de la membrana y de cada soluto en particular, un equilibrio puede conseguirse en segundos si la distancia es de micras, pero puede subir a varias horas si la distancia de difusión se incrementa a milímetros?

La ósmosis es un caso especial de difusión en el que es el movimiento del disolvente el que se estudia, yse define en función de los solutos. Laósmosis es el movimiento del agua desde soluciones con baja concentración de soluto hasta soluciones con alta concentración de soluto y la presión osmótica es la presión hidrostática que se genera a través de una membrana semipermeable con un gradiente de concentración al lado y lado, depende del número de partículas de la solución.?

La presión osmótica se suele expresar en osmoles y depende exclusivamente del número de partículas disueltas (moles) por unidad de volumen, con independencia de su carga eléctrica, peso o fórmula 
química, es por tanto una propiedad coligativa (es decir las propiedades colectivas que una solución tiene cuando estos compuestos están presentes), los productos criopreservados se deben almacenar a temperaturas desde $-133^{\circ} \mathrm{C}$ (vapores de nitrógeno líquido) a -196ㄷ (nitrógeno líquido). A estas temperaturas no existen fenómenos de difusión ni energía térmica suficiente para llevar a cabo las reacciones químicas y por tanto las dificultades de la congelación no derivan de la permanencia a temperaturas bajas sino de los procesos de congelación y descongelación. ${ }^{10}$

La lesión celular crio inducida se explica en función de la formación de hielo intracelular y el estrés osmótico al que se ven sometidas las membranas celulares durante la congelación, Merryman propone la hipótesis del volumen celular mínimo que relaciona el efecto de la deshidratación producida durante la concentración de solutos y la muerte celular con la vuelta a las condiciones isotónicas después de la congelación (choque osmótico), el volumen celular mínimo se basa en que el volumen se reduce en relación al aumento de la osmolaridad extracelular, a medida que la célula pierde volumen por la pérdida de agua, la compresión del contenido citoplasmático aumenta la resistencia de la célula a seguir perdiendo volumen, y al excederse la resistencia física de la membrana se producirán cambios irreversibles en su permeabilidad, en este caso los crioprotectores actuarían reduciendo por sus propiedades coligativas la cantidad de hielo formado a una temperatura determinada. ${ }^{11}$

\section{Agentes crioprotectores (ACP)}

Los criopreservantes son sustancias hidrosolubles y de baja toxicidad, que disminuyen el punto eutéctico de una solución dada, (punto en el cual una composición dada de $A$ y $B$ solidifica como un elemento puro), el descenso del punto eutéctico implica que se alcanzará una concentración dada de solutos a una temperatura menor, de forma que la célula estará mas deshidratada y el gradiente osmótico al que estará sometido será menor.
Bioquímicamente es posible distinguir tres tipos de crioprotectores, los alcoholes (metanol, etanol, propanol, 1-2 propanediol y glicerol), azúcares (glucosa, lactosa, sucrosa, sacarosa) y el dimetil sulfóxido, los crioprotectores pueden clasificarse también en agentes penetrantes y no penetrantes de acuerdo a la permeabilidad celular. ${ }^{12,13}$

\section{Los crioprotectores penetrantes}

Son de bajo peso molecular y permeables a través de la membrana celular. Son utilizados: el glicerol, el dimetilsulfoxido (DMSO) y propanediol (PROH).

El dimetil sulfóxido es un solvente bipolar aprótico, hidrosoluble, de bajo peso molecular; desde el descubrimiento de sus propiedades crioprotectoras por Lovelock en $1959,{ }_{1}^{14}$ el DM SO se ha usado como un crioprotector. Su acción crioprotectora se atribuye principalmente a su habilidad de prevenir acumulación excesiva de electrolitos y otras sustancias durante el proceso de congelamiento, y la formación de cristales de hielo que rompen la estructura de la membrana, su bajo peso molecular permite la entrada rápida través de la membrana celular,12 modula la estabilidad y fases de la bicapa de los fosfolípidos, así como también afecta los procesos de solvatación de agua. Se han sugerido las interacciones electrostáticas de D M SO con fosfolípidos lo cual parece ser crítico para la crioprotección de la membrana. ${ }^{13} \mathrm{El}$ 1-2. propanediol ha sido utilizado principalmente para congelación de blastocistos y embriones en estado de preimplantación de humanos y otras especies. ${ }^{13}$

\section{Agentes crioprotectores no-penetrantes}

Son sustancias de alto peso molecular, efectivas a velocidades altas de congelación, son importantes por ejercer su acción crioprotectora promoviendo la rápida deshidratación celular y suelen usarse asociados a los agentes penetrantes. Los más utilizados son: sacarosa, glucosa, dextrosa y dextrano. Estos compuestos generalmente son polímeros que 
forman puentes hidrógeno con el agua, reduciendo la actividad de agua a una magnitud mucho mayor que la que se predeciría por su concentración molar (ellos no obedecen la ley de Raoult).

La adición del criopreservante per se genera estrés osmótico sobre las células porque aumenta la osmolaridad del medio. Las células inicialmente se deshidratan para compensar la fuerza osmótica inducida por la presencia de los ACP y después se hidrata. La definición de los parámetros biofísicos de cada célula y el estudio de la interacción con los ACP durante la congelación y descongelación de las células deben ser definidos para establecer los límites físicos que aseguren la supervivencia de la célula.

\section{Estud lio de los parámetros biofísicos de las células}

Las células se comportan como osmómetros, por lo tanto variarán su volumen en respuesta alos cambios osmóticos extracelulares, aś las células pierden 0 captan agua según se expongan a condiciones hipo o hiper osmóticas, respectivamente; los movimientos de agua y crioprotectores a través de la membrana celular durante la criopreservación se rigen por diversos parámetros biofísicos que deben ser definidos para cada tipo celular a diferentes temperaturas.

Los más estudiados son: 1.) el volumen osmóticamente inactivo (que se define como el agua que nunca dejará el interior celular en respuesta a un aumento de concentración de solutos en el espacio extracelular por estar asociado a las macromoléculas y estructuras intracelulares) que esta relacionado con la hipótesis de volumen mínimo de M eryman ${ }^{11}$ y que se puede conocer mediante micro perfusión en un sistema de micro manipulación, ${ }^{15}$ 2.) la permeabilidad de la membrana celular (al agua, criopreservantes, solutos) que puede ser estudiada entre otras por un contador electrónico de partículas con un software específico, criomicroscopía $2^{15-17}$ y la técnica de escaneo calorimétrico diferencial (DSC) basada en que durante la deshidratación de la célula, sin congelación intracelular, se aumenta la concentración de electrolitos, sustratos, cofactores, proteínas celulares y asimismo se aumenta el transporte de agua al medio externo en congelación, este último fenómeno genera liberación de calor de fusión proporcional a la cantidad de agua removida de la célula. La célula es entonces lisada y el DSC mide repetidamente el calor de fusión emitido, estas diferencias son utilizadas para calcular el volumen de agua que ha atravesado la membrana; de esta última se puede deducir el volumen como una función de temperatura subcero, ${ }^{18} 3$.) la relación área de superficie celular a volumen que es variable entre las células. En la tabla 1 se observa el perfil biofísico de la célula CD34+.

Un banco de células debe tener disponible los ensayos de viabilidad ya que estos son necesarios y pueden ser predictivos de la calidad de una muestra entendiendo que la viabilidad no es sinónimo de la vida. Los índices de viabilidad son específicos al mecanismo así como a la muestra biológica y la función moderada (una muestra particular puede tener más de un índice de viabilidad). La función que debe mantener la célula descongelada in vivo es la función ideal para medir un índice de viabilidad. La medición de esa viabilidad debe ser realizada por estudios de citometría mediante la incorporación del 7AAD $y$, en algunos casos, por ensayos de cultivos clonogénicos que aseguren la funcionabilidad del producto descongelado. ${ }^{20}$

\begin{tabular}{|c|c|c|c|c|c|}
\hline abla 1 & & & & & \\
\hline CELULA & $\begin{array}{l}\text { Volumen } \\
\text { celular cc }\end{array}$ & $\begin{array}{c}\text { Volumen } \\
\text { osmóticamente } \\
\text { inactivo cc }\end{array}$ & $\begin{array}{l}\text { Permeabilidad } \\
\text { agua } \mathrm{cm} / \mathrm{min}\end{array}$ & $\begin{array}{l}\text { Permeabilidad } \\
\text { DMSO cm/min, }\end{array}$ & Ref \\
\hline CD34t & $2,38 \times 10-10$ & $0,27 \times 10-10$ & $20^{\circ} \mathrm{C} 5 \times 10$ & $20^{\circ} \mathrm{C} 0,91 \times 10-3$ & $16,18,19$ \\
\hline
\end{tabular}




\section{Métodos de criopreservación}

Podemos clasificarlos de acuerdo a la velocidad de congelamiento y descongelamiento en protocolos de congelación lenta-descongelación lenta, congelación lenta-descongelación rápida en las cuales la adición del crioprotector suele hacerse por pasos y el descenso de la temperatura se realiza lentamente en un congelador programable. La descongelación rápida se hace rápidamente a temperatura ambiente o en un baño de agua a $30^{\circ} \mathrm{C}$ para evitar la recristalización.

La congelación ultrarrápida fue originalmente descrita para la congelación de embriones, por Trouson en 1986. Implica la rápida deshidratación celular, utilizando altas concentraciones de crioprotector, usualmente DMSO y sacarosa, seguida de inmersión en nitrógeno líquido.

La vitrificación tampoco requiere la utilización de un congelador programable; se basa en la congelación rápida en una mezcla de altas concentraciones de crioprotectores, que a bajas temperaturas aumentan su viscosidad formando un sólido amorfo, sin formación de hielo. ${ }^{4}$

\section{Bancos de criopreservación}

Criopreservación de ovocitos: la condición de esterilidad iatrogénica posterior a quimioterapia 0 radioterapia en patologías neoplásicas, puede ser evitada con la criopreservación de ovocitos, adicionalmente, mujeres que sufren otras patologías del sistema reproductivo (falla ovárica prematura, endometriosis, quistes, infecciones pélvicas), 0 mujeres quienes desean postergar la maternidad pueden asegurar su potencial de fertilidad usando esta técnica. ${ }^{13}$

La ovogénesis involucra cambios bioquímicos y estructurales en el núcleo, el oolema y el complejo oocito-granulosa, por lo tanto los elementos del citoesqueleto, la progresión del ciclo celular, la morfogénesis del huso, entre otros, son importantes factores determinantes para el desarrollo de protocolos de criopreservación específicos para cada estado de madurez. ${ }^{21} \mathrm{El}$ almacenamiento y criopreservación del ovocito han sido mucho más complejos que los del gameto masculino y de embriones. Los ovocitos son extremadamente sensibles a la temperatura con eventual despolimerización de los microtúbulos del huso causados por los crioprotectores o los cristales de hielo formados durante la congelación y descongelación, la separación normal de las cromátidas puede ser afectada durante estos procesos induciendo así aneuploidias; el bajo número de embarazos posterior a la criopreservación de ovocitos refleja las dificultades técnicas de los procedimientos de congelación. ${ }^{22}$

Por otra parte, el ovocito es una gran célulay por lo tanto tiene una baja relación de área de superficie a volumen, esto impide la sobrevida post criopreservación viéndose alterada principalmente la zona pelúcida por liberación prematura del contenido de los gránulos corticales, disrupción de la membrana plasmática, desorganización extensiva del ooplasma y alteraciones en el citoesqueleto. ${ }^{3}$ La evidencia de los daños presentados en ovocitos congelados condujo al desarrollo de congelación de ovocitos en estados más inmaduros como es el caso de los folículos primordiales y vesículas germinales, con tasas de éxito aún limitadas, ya que resulta difícil lograr su desarrollo in vitro en estadios más maduros. Esta misma dificultad Ilevó a los investigadores a diseñar protocolos de congelación para ovocitos en metafase II. Variedad de métodos han sido expuestos, algunos utilizando DMSO y posteriormente el 1,2 PROH, como también tasas de congelamiento lentas de 0,3$0,5^{\circ} \mathrm{C} / \mathrm{min}$ hasta llegar a $-40^{\circ} \mathrm{C} 0-80^{\circ} \mathrm{C} .{ }^{23,24} \mathrm{O}$ tras técnicas varían la temperatura, el tiempo de exposición al crioprotector, la temperatura para realizar el seeding y la utilización de sucrosa en conjunto con otros CPA. Actualmente se han desarrollado protocolos de congelación ultrar rápida-descongelación rápida, utilizando altas concentraciones de crioprotectores previniendo así la formación de cristales de hielo y la inducción de un medio amorfo y vítreo. Trounson fue el primero en aplicar esta estrategia a la criopreservación de ovocitos por la inmersión directa del ovocito en el nitrógeno líquido (conge- 
lación ultrarrápida) y la subsiguiente descongelación hechaa $37^{\circ} \mathrm{C}$ en un baño de agua. ${ }^{25} \mathrm{En}$ otro proceso llamado vitrificación, una solución de crioprotectores altamente concentrados se solidifica durante la congelación sin la formación de cristales de hielo, en un fluido altamente viscoso y súper enfriado, este método demostró al gunas ventajas claras compradas con la congelación lenta debido a que es evitada la formación de hielo extracelular. La combinación de una alta tasa de enfriamiento (cerca de los $1.500^{\circ} \mathrm{C} /$ $\mathrm{min}$ ) y altas concentraciones de crioprotector tales como DM SO, acetamida, polietilenglicol (PEG), son requeridos para la vitrificación. Trounson reporta aceptables tasas de sobrevida y fertilización pero bajas tasas de clivaje, quizás debido a daños en el citoesqueleto.

En términos generales el crioprotector en la solución determina una leve disminución en el punto crioscópico de esta (-2ํㅜ $\left.0-3{ }^{\circ} \mathrm{C}\right)$. El efecto protector es principalmente un resultado de la capacidad de estas moléculas de formar uniones de hidrógeno que alteren la estructura cristalizada normal del agua. A través de sus grupos $\mathrm{OH}$, el glicerol y el PROH por ejemplo, pueden formar uniones de hidrógeno con el agua mientras que el DMSO lo hace a través de los átomos de oxígeno. Los CPA reducen el efecto dañino de la alta concentración de electrolitos en la porción de agua en su estado líquido. En sistemas que son constituidos por dos fases a una presión constante tales como el hielo y el agua, la concentración total de solutos en la fase líquida es constante y, debido a esto la adición de CPA reduce la cantidad de agua que se cristaliza. ${ }^{26}$

Otro paso importante en la criopreservación de ovocitos es la remoción del CPA permeable del citoplasma. El proceso consiste en pasaje del ovocito a través de una serie de soluciones que contienen concentraciones gradualmente disminuidas. Como resultado del efecto de la presión osmótica, las células podrían explotar si se coloca en un medio sin CPA inmediatamente después de descongelarlas. La escogencia de la tasa de descongelación depende de la tasa a la cual haya sido congelada.
Congelación de espermatozoides: a pesar de que los espermatozoides fueron los primeros tipos de células crio preservadas, ${ }^{27}$ intentos de mejoramiento para su criopreservación son objeto de investigación, principalmente por la pobre sobrevida de estas células en pacientes con infertilidad y problemas oncológicos. No hubo avances significativos hastael descubrimiento de las propiedades crioprotectoras del glicerol en espermatozoides de toro, abriendo así una opción viable para campos como la reproducción asistida en humanos. El éxito relativo de la criopreservación del semen ha mostrado avances significativos en el intercambio internacional de animales genéticamente superiores, biotecnología, conservación de especies en extinción y medicina reproductiva humana.

Lacriopreservación deespermatozoides humanos y bovinos ha evolucionado empíricamente, usando tasas de congelamiento de hasta $100-200^{\circ} \mathrm{C} / \mathrm{min}$ y medios basados en glicerol con citrato de yema de huevo, sin embargo otros estudios sugieren tasas de sobrevida exitosa utilizando etilenglicol. ${ }^{28} \mathrm{Sin}$ embargo, estos protocolos deben ser re-examinados con estrecha atención al daño causado por la criopreservación.

La caracterización de la criobiología del espermatozoide se empezó hace aproximadamente veinte años, determinando diferentes parámetros de los espermatozoides, entre ellos los cambios bioquímicos, estatus energético, integridad de la membrana, temperatura de transición de fase de la membrana lipidica, integridad de elementos subcelulares y morfología de acrosoma. ${ }^{29}$

Cuando el ACP es agregado de forma abrupta se puede observar daño en la membrana plasmática, región acrosomal y configuración de la cola. ${ }^{30}$

Muchos laboratorios utilizan el método simple y rápido de suspender las pajuelas o las ampollas en vapores de nitrógeno líquido por un periodo adicional antes de sumergirlas definitivamente dentro del nitrógeno líquido por largos periodos de tiempo. Este método no requiere equipos especializados $y$, aunque no es ideal, puede dar lugar a tasas de vida 
satisfactorias. Los principales problemas incluyen tasas de enfriamiento no uniformes entre alícuotas del mimo eyaculado y dificultades en mantener reproducibles las condiciones de congelación. Congeladores programables en los cuales circulan los vapores de nitrógeno líquido en una tasa controlada permiten curvas de enfriamiento más reproducibles, permitiendo mantener las temperaturas para hacer el seeding manual. ${ }^{31}$

Estudios más recientes han sugerido que la permeabilidad de la membrana espermática a temperaturas supracero es más alta de las de otros espermatozoides de mamíferos. Esta alta permeabilidad puede ser por la presencia de proteínas que forman canales selectivos para el agua; se ha sugerido que las células con alta permeabilidad al agua y baja energía de activación ( $<6-7 \mathrm{kcal} / \mathrm{mol}$ ) tienen canales específicos para el agua o aquaporinas AQP, siendo esta una explicación teórica para los espermatozoides. ${ }^{32}$ Se ha reportado abundante expresión de AQP7 y AQP8 en testículos. Estudios indican que AQP7 aparece solamente en estados tardíos de la espermatogénesis y está presente en pequeñas cantidades en espermatozoides maduros.

Congelación de embriones: en humanos, el primer nacimiento de un embrión congelado ocurrió en 1983 en Australia por Trounson, a partir de este momento la embrio-congelación se extendió rápidamente con la ayuda de procedimientos biológicos optimizados y simplificados tales como el uso de PROH y sucrosa como crioprotectores llegando a ser una indispensable extensión de las ART. ${ }^{32}$

Tres medidas técnicas deben ser usadas para un mejor control del periodo inestable de cambio de fase en la solución que rodea al embrión y en el embrión mismo, estas son:

\section{El control de las tasas de congelación}

y descongelación: a medida que la tasa de enfriamiento aumenta, la probabilidad de que el hielo intracelular pueda formarse también aumenta. Para cada célula hay una óptima tasa de enfriamiento la cual depende de varios factores, particularmente el volumen celular y la composición de la membrana. Las más altas tasas de sobrevida son obtenidas con una velocidad de enfriamiento de aproximadamente $0,3 \circ \mathrm{C} / \mathrm{min}$. Para cigotos y embriones con una tasa de congelación de 4-8으/min.

2. Crioproteccion química: la crioprotección ha sido demostrada paraembriones humanos así como para otras células, hasta ahorase haevidenciado que el glicerol entray dejalascélulas embriónicas mucho más lento queel DM SO y el PROH, el propanediol tiene una toxicidad más baja aaltas concentraciones que el glicerol o el DMSO. La adición de algunos azúcares mono-di o tri sacáridos no entran a la célula pero actúan como crioprotectores incrementando la presión osmótica del medio externo. Durante los procesos de descongelación, esta propiedad osmótica de los compuestos no permeables puede también ser usada para limitar la entrada de agua durante el procedimiento de remoción del crioprotector, protegiendo por tanto al embrión de la excesiva y rápida rehidratación.

3. Enucleación del hielo: las soluciones crioprotectoras usualmente alcanzan temperaturas tan bajas como $-150 \mathrm{C}$ antes de que el hielo sea formado. Esto es Ilamado súper-enfriamiento y este fenómeno produce calor latente, el cual se ha visto en la curva de enfriamiento como un corto espacio en la disminución lineal programada de la temperatura. Evitar el súper-enfriamiento es esencial para el éxito de la embrio-congelacion. La forma usual de evitar este súper-enfriamiento es inducir la formación de hielo a cerca de -7으 con un leve contacto en la superficie de los viales o pajuelas que contengan los embriones con unas pinzas, previamente enfriadas en nitrógeno líquido. Las pinzas son retiradas tan pronto como los primeros cristales sean vistos como un punto blanco en la solución extracelular y la caída programada en la temperatura es reiniciada. Este seeding de hielo puede ser hecho automáticamente en algunos congeladores programables pero es menos confiable que la inducción de hielo mecánica visualmente controlada. ${ }^{33}$ 


\section{Protocolos de embrio-congelación:}

Congelación lenta: utilizando PROH para zigotos 0 para embriones en estadio temprano, D MSO para estados divididos y glicerol parablastocistos. U sando PROH 1,5 moles/Lt y sucrosa 0,1 moles/Lt, a una tasa de $0,3^{\circ} \mathrm{C} / \mathrm{min}$., hasta $-30^{\circ} \mathrm{C}$.

Congelación ultrarrápida: utilizando 2,0-3,0 M de DMSO y 0,25-0,5 M de sucrosa.

Vitrificación: utilizando 40\% de Etilenglicol.

La congelación de embriones puede ser realizada en diferentes estadios de desarrollo, teniendo cada uno diferentes tasas de sobrevida, así como también ventajas y desventajas. La eficiencia de un programa de congelación es evaluada por la observación de la integridad morfológica del embrión en descongelación, la habilidad de clivar in vitro y su capacidad de implantación.33

\section{Banco de células madre de sangre de cordón umbilical}

La sangre de cordón umbilical (SCU) contiene una elevada cantidad de progenitores hemopoyéticos circulantes desde la semana 14 de embarazo, condición que es permanente hasta el momento del parto en que su número es condicionado a ciertas condiciones ginecoobstétricas, estas células tienen la capacidad de repoblación medular a largo plazo. Como consecuencia, dicho tejido se ha convertido en alternativa para trasplante.

Las células nucleares se obtienen por centrifugación diferencial en un sistema de circulación cerrado para disminuir contaminantes, se criopreservan en bolsa con doble compartimiento utilizando crioprotectores intracelulares (DMSO) y crioprotectores extracelulares (D extran). Para el congelamiento de la unidad de cordón se utiliza una curva de congelamiento programada en un equipo que disminuye gradualmente $1^{\circ} \mathrm{C}$ por minuto a $4^{\circ} \mathrm{C}$; primero se agrega la solución crioprotectora de manera gradual para lograr el equilibrio osmótico ( 5 minutos) y se utiliza una curva de congelamiento programada en un equipo que disminuye gradualmente $1^{\circ} \mathrm{C}$ por minuto hasta llegar a $-10^{\circ} \mathrm{C}$, se induce el proceso de nucleación disminuyendo abruptamente $\mathrm{a}-60^{\circ} \mathrm{C}$ posteriormente es llevado a $-20^{\circ} \mathrm{C}$ y disminuye gradualmente hasta- $120^{\circ} \mathrm{C}$ una vez alcanzada dicha temperatura las células son guardadas en tanques de nitrógeno líquido para su posterior aplicación. ${ }^{34}$

\section{CONCLUSIÓN}

Cada tipo celular debe ser congelado conociendo el perfil biofísico de la célula, el cual dictará mediante ensayos de permeabilidad y volumen osmóticamente inactivo con diferentes criopreservantes y/o soluciones criopreservantes (mezcla de crioprotectores penetrantes y no penetrantes) el mejor protocolo de criopreservación de esa célula. Es importante asegurar un sistema de seguridad, de continuidad del nitrógeno líquido y ensayos de control de calidad por medio de pruebas de viabilidad.

\section{REFERENCIAS}

1. WoodsEJ, Benson JD, AgcaY, Critser JK. Fundamental cryobiology of reproductive cells and tissues. Cryobiology 2004;48:146-56.

2. Mazur P. Freezing of living cells: mechanisms and implications. Am J Physiol 1984,247:C125-42.

3. Shaw JM, Oranratnachai A, Trounson AO. Fundamental cryobiology of mammmalian oocyte and ovarian tissue. Theriogenology 2000;53:59-72.

4. Boiso I. Criobiología. Revista I beroamericana de Fertilidad 2001;18(4).

5. Singer S), Nicholson GL. The fluid mosaic model of the structure of cell membranes. Science 1972;175:720-31.

6. Lotan RN. Advanced Cell Biology. NY: Ed van Nostrand; 1981.

7. Mathews K.M, van H oldeKE, Ahern KG. Biochemistry. Third edition. Addison Wesley; 2003 p. 363-92.

8. Seidel GE Jr. Modifyng oocytes and embryos to improve their cryopreservation. Theriogenology 2006:65:228-35

9. MendozaJA, Dulin P, Warren T. The lower hydrolysis of ATP by the stress protein GroEL is a major factor responsible for the diminished chaperonin activity at low temperature. Cryobiology 2000;41:319-23.

10. Loken SD, D emetrik DJ. A novel method for freezing and storing research tissue bank specimens. Hum Pathol 2005;36:977-80. 
11. Meryman HT. O smotic stress as a mechanism of freezing injury. Cryobiology 1971;8:489-500.

12. GarcíaJ V. Criopreservadores concepto y manejo. Biol Clin H ematol 1984;6(219).

13. Porcu E. Oocyte Criopreservation. En: Gardner DK, Weissman A, Howles CM, Shoham Z (eds). Textbook of Assisted Reproductive Techniques: Laboratoryand Clinical Perspectives. London, UK: Martin D unitz Ltd; 2001.

14. Lovelock JE. The haemolysis of human red blood cells by freezing and thawing. Biochim Biophys Acta 1953;10:414-26.

15. Hunt CJ, Armitage SE, Pegg DE. Cryopreservation or umbilical cord blood: 2. Tolerance of CD 34(+ ) cells to multimolar dimethyl sulphoxide and the effect of cooling rate on recovery after freezing and thawing. Cryobiology 2003;46:76-87.

16. Woods EJ, Lui J, Derrow CW, Smith FO, Williams DA, Critser JK. Osmometric and permeability characteristics of human placental/umbilical cord blood CD 34+ cells and their application to cryopreservation. J Hematother Stem Cell Res 2000;9:161-73.

17. Devireddy RV, Swanlund DJ, Roberts KP, Pryor $J \mathrm{~L}$, Bischof JC. The effect of extracellular ice and cryoprotective agents on the water permeability parameters of human sperm plasma membrane during freezing. Hum Reprod 2000;15:1125-35.

18. Gilmore JA, Liu J, Woods EJ, Peter AT, Critser JK. Cryoprotective agent and temperature effects on human sperm membrane permeabilities: convergence of theoretical and empirical approaches for optimal cryopreservation methods. H um Reprod 2000;15:335-43.

19. Hunt CJ, Armitage SE, Pegg DE. Cryopreservation or umbilical cord blood: 1. Osmotically inactive volume, hydraulic conductivity and permeability of CD34(+ ) cells to dimethyl sulphoxide. Cryobiology 2003;46:61-77.

20. Yang JP, Acker JP, Cabuhat M, M CGann LE. Effects of incubation temperature and time after thawing on viability assessment of peripheral hematopoietic progenitor cells cr yopreser ved for transplantation. Bone Marow Transplant 2003:1021-6.

21. Albertini DF. The cytoskeleton as a target for chill injury in mammalian cumulus oocyte complexes. Cryobiology 1995;32:551-62.
22. Van Blerkom J, Davis PW. Citogenetics cellular and developmental consequences of criopreservation of immature and mature mouse and human oocytes. Microsc Res Tec 1994;27:165-93.

23. Bernard A, Fuller BJ. Cryopreservation of human oocytes: areview of current problems and perspectives. H um Reprod U pdate 1996;2:193-207.

24. ParksJE, Ruffing NA. Factor affecting low temperature survival of mammalian oocyte. Theriogenology 1992:37:59-73.

25. Trounson A. Preservation of human eggs and embryos Fertil Steril 1986;46:1-12.

26. Friedler S, Giudice LC, Lamb EJ. Cryopreservation of embryos and ova. Fertil Steril 1988;49:743-64.

27. Polge CA, Smith AV, Parkes AS. Revival the spermatozoa after vitrification and dehydratation at low temperature. Nature 1949;164:666.

28. Gilmore JA, Liu J, Gao DY, Critser JK. Determination of optimal crioprotectans and procedures for their addition and removal for human spermatozoa. H um Reprod 1997;12:112-8.

29. Drobnis EZ, Crowe LM, Berger T, Anchordoguy TJ, Overstreet JW, Crowe JH. Cold shock damage is due to lipid phasetransitionsin cell membranes: ademonstration using sperm as a model. J Exp Zool 1993;19:432-7.

30. Willoughby CE, Mazur P, Peter AT, Crister JK. $O$ smotic tolerance limits and properties of murine spermatozoa. Biol Reprod 1996;55:715-27.

31. M claughlin E, Ford WC, H ull M G. A comparison of the freezing of human semen in the uncirculated vapour about liquid nitrogen and in a commercial semiprogrammable freezer. Hum Reprod 1990;5:724-8.

32. Trounson A, Mohr L. Human pregnancy following cryopreservation, thawing and transfer of an eigth-cell embryo. Nature 1983;305:707-9.

33. MandelbaumJ, Menezo Y. Embryo cryopreservation in humans. En: Gardner DK, Weissman A, H owles CM, Shoham Z (eds). Textbook of Assisted Reproductive Techniques: Laboratory and Clinical Perspectives. London, U K: Martin Dunitz Ltd; 2001.

34. Yang H, Zhao A, Acker JP, Liu JZ, Akabutu J, M cGann LE. Effect of dimethyl sulfoxide on post thaw viability assessment of CD 45+ and CD 34+ cells of umbilical cord blood and mobilized peripheral blood. Cryobiology 2005;10:165-75. 